\title{
DNA methylation loci in placenta associated with birthweight and expression of genes relevant for early development and adult diseases
}

Fasil Tekola-Ayele ${ }^{1 *} \mathbb{D}, X^{\prime}$ Xuehuo Zeng ${ }^{2}$, Marion Ouidir', Tsegaselassie Workalemahu', Cuilin Zhang ${ }^{1}$, Fabien Delahaye ${ }^{3,4}$ and Ronald Wapner ${ }^{5}$

\begin{abstract}
Background: Birthweight marks an important milestone of health across the lifespan, including cardiometabolic disease risk in later life. The placenta, a transient organ at the maternal-fetal interface, regulates fetal growth. Identifying genetic loci where DNA methylation in placenta is associated with birthweight can unravel genomic pathways that are dysregulated in aberrant fetal growth and cardiometabolic diseases in later life.

Results: We performed placental epigenome-wide association study (EWAS) of birthweight in an ethnic diverse cohort of pregnant women $(n=301)$. Methylation at 15 cytosine-(phosphate)-guanine sites (CpGs) was associated with birthweight (false discovery rate (FDR) <0.05). Methylation at four $(26.7 \%)$ CpG sites was associated with placental transcript levels of 15 genes (FDR $<0.05$ ), including genes known to be associated with adult lipid traits, inflammation and oxidative stress. Increased methylation at cg06155341 was associated with higher birthweight and lower FOSL1 expression, and lower FOSL1 expression was correlated with higher birthweight. Given the role of the FOSL1 transcription factor in regulating developmental processes at the maternal-fetal interface, epigenetic mechanisms at this locus may regulate fetal development. We demonstrated trans-tissue portability of methylation at four genes (MLLT1, PDE9A, ASAP2, and SLC20A2) implicated in birthweight by a previous study in cord blood. We also found that methylation changes known to be related to maternal underweight, preeclampsia and adult type 2 diabetes were associated with lower birthweight in placenta.
\end{abstract}

Conclusion: We identified novel placental DNA methylation changes associated with birthweight. Placental epigenetic mechanisms may underlie dysregulated fetal development and early origins of adult cardiometabolic diseases.

Clinical trial registration: ClinicalTrials.gov, NCT00912132

Keywords: Placenta, Birthweight, Fetal growth, DNA methylation, Transcriptomics, Expression quantitative trait methylation (eQTM), Developmental origins of health and disease (DOHaD)

\footnotetext{
* Correspondence: ayeleft@mail.nih.gov

'Epidemiology Branch, Division of Intramural Population Health Research, Eunice Kennedy Shriver National Institute of Child Health and Human Development, National Institutes of Health, 6710B Rockledge Dr, room 3204, Bethesda, MD 20892, USA

Full list of author information is available at the end of the article
}

(c) The Author(s). 2020 Open Access This article is licensed under a Creative Commons Attribution 4.0 International License, which permits use, sharing, adaptation, distribution and reproduction in any medium or format, as long as you give appropriate credit to the original author(s) and the source, provide a link to the Creative Commons licence, and indicate if changes were made. The images or other third party material in this article are included in the article's Creative Commons licence, unless indicated otherwise in a credit line to the material. If material is not included in the article's Creative Commons licence and your intended use is not permitted by statutory regulation or exceeds the permitted use, you will need to obtain permission directly from the copyright holder. To view a copy of this licence, visit http://creativecommons.org/licenses/by/4.0/ The Creative Commons Public Domain Dedication waiver (http://creativecommons.org/publicdomain/zero/1.0/) applies to the data made available in this article, unless otherwise stated in a credit line to the data. 


\section{Background}

Birthweight is a complex multifactorial trait relevant for health and disease in childhood and adulthood. Abnormal birthweight has been consistently associated with infant mortality and morbidity, childhood obesity, and cardiometabolic diseases in adulthood [1-3]. Complex interplays between genetic and environmental influences play important roles in regulating fetal growth and development [4]. Epigenetic mechanisms such as DNA methylation may represent the regulatory links between genetic and environmental influences on birthweight [5]. Identifying DNA methylation loci that are associated with birthweight can give clues to detect molecular biomarkers of aberrant fetal growth and cardiometabolic diseases in later life. The placenta is known for its prominent relevance in fetal growth and development due to its roles in nutrient transport, immune regulation, and hormonal functions [6]. Compromised placental function has often been associated with aberrant fetal growth [7] and risk of cardiometabolic diseases in later life [8].

DNA methylation in placenta is critical for placental development and regulation of trophoblast invasion, factors important for fetal growth outcomes [9, 10]. The DNA methylation profile of the placenta undergoes dynamic changes [11-13], potentially due to cumulative environmental exposures, adaptive changes in placental cell composition, and genetic regulation [13]. DNA methylation in placenta regulates gene expression and cellular function and may be one mechanism by which environmental exposures and genetic variation influence fetal growth. Therefore, DNA methylation loci associated with birthweight can point to molecular signatures of the intrauterine environment and may lend insights to understand the links between fetal growth and cardiometabolic diseases in later life. Epigenome-wide association studies (EWASs) have identified several cord blood DNA methylation cytosine-phosphate-guanine sites (CpGs) associated with birthweight [14-18]. Although cord blood is a more accessible tissue for genomic studies, the placenta may be a more biologically relevant tissue for studying the epigenetic regulation of fetal growth and development. Previous studies in placenta reported that birthweight status is significantly associated with long interspersed nuclear elements (LINE)-1 methylation in placenta $[19,20]$, global placental DNA methylation [21], and methylation levels at selected candidate gene regions [22-25] and at CpGs assayed using the HumanMethylation27 BeadChip array [26, 27]. An EWAS of birthweight using placental samples profiled using more recently developed dense DNA methylation arrays is warranted to unravel novel genetic loci.

In this study, we examined the association between birthweight and epigenome-wide DNA methylation in placental samples obtained from participants of the
Eunice Kennedy Shriver National Institute of Child Health and Human Development (NICHD) Fetal Growth Studies-Singletons cohort [28, 29]. For CpGs found to be significantly associated with birthweight in our analysis, we investigated the associations between methylation levels at the CpGs and expression of the proximal genes in placenta. We also tested for correlations between placental expression of those genes and birthweight. Pathway analyses, functional annotations, and genetic variants associated with DNA methylation were explored to understand the biological context that may explain the relationship between the differentially methylated CpGs and birthweight. The placenta may harbor the epigenetic links between maternal cardiometabolic status, fetal growth and risk of cardiometabolic diseases in later life. Therefore, for CpGs in offspring tissues known to be related to maternal perinatal cardiometabolic traits and CpGs in adult tissues known to be related to cardiometabolic diseases, we tested whether methylation in placenta was associated with birthweight. Our findings of novel genomic loci associated with birthweight and overlaps with adult cardiometabolic diseases lend insights into the pathophysiology of fetal growth and potential molecular targets to prevent cardiometabolic diseases in later life.

\section{Results \\ Data set}

We used DNA methylation data measured using Illumina's Infinium Human Methylation450 Beadchip (Illumina Inc., San Diego, CA) on placentas obtained at delivery from 301 pregnant women who participated in the NICHD Fetal Growth Studies-Singletons [28, 29]. The self-reported race/ethnic profiles of the 301 women were 102 Hispanics, 77 Whites, 72 Blacks, and 50 Asians. None of the pregnant women smoked cigarettes in the past 6 months prior to conception. The mean $( \pm$ standard deviation (SD)) birthweight and gestational age at delivery were $3165( \pm 451) \mathrm{g}$ and $39.5( \pm 1.1)$ weeks, respectively. Detailed characteristics of participants of the NICHD Fetal Growth Studies and the 301 women and neonates included in the present study have been described previously [28, 29]. The major characteristics of the 301 women were similar to those in the overall NICHD Fetal Growth Studies cohort, except prepregnancy body mass index (Additional Table 1). Gene expression profile of a subset of the placental samples $(n$ = 80) was obtained from RNA sequencing performed on the Illumina HiSeq2000 system. The self-reported race/ ethnic profiles of the 80 women were 28 Hispanics, 24 Whites, 20 Blacks, and 8 Asians. Both DNA methylation and gene expression profiles were available in a total of 75 placental samples [29]. 


\section{Differentially methylated CpGs associated with birthweight}

We performed EWAS to identify CpGs significantly associated with birthweight using linear regression models adjusted for neonatal sex, gestational age at delivery, race/ethnicity, five methylation plate representing batch of the 96-well plate on which samples were assigned, top 3 methylation principal components (PCs), top 10 genotype-based PCs representing population stratification due to genetic ancestry, and putative cell mixtures derived from components of surrogate variable analysis (SVA) to account for confounding by cell-type composition [30]. We found that methylation at $15 \mathrm{CpGs}$ was associated with birthweight at a false discovery rate (FDR) of 0.05. The changes in methylation beta values associated with $10 \mathrm{~g}$ higher birthweight were found to be highest for cg10806146 (SLC20A2) ( $\beta=0.04 \%$, 95\% CI $0.02 \%$ to $0.06 \%), \operatorname{cg} 15936066$ (SLC20A2) ( $\beta=0.03 \%, 95 \%$ CI $0.01 \%$ to $0.04 \%)$, and cg09467508 (intergenic) $(\beta=$ $0.03 \%, 95 \%$ CI $0.01 \%$ to $0.04 \%$ ). Out of the 15 CpGs, 12 (80\%) exhibited increased DNA methylation with higher birthweight. Ten CpGs were located in the gene body (UBXN11, ASAP2, TMEM107, PPP3R1, CNIH2, MLLT1, $C 2$ orf60, C8orf58, $L B X 2$, and $P D E 9 A$ ), three were within the $5^{\prime}$ untranslated region annotating two genes (SLC20A2 and MPG), and 2 were in intergenic regions (Fig. 1, Table 1). None of the $15 \mathrm{CpGs}$ was associated with gestational age at delivery (Additional Table 2).

\section{Association between DNA methylation at birthweight- associated $\mathrm{CpGs}$ and gene expression}

We examined whether the $15 \mathrm{CpGs}$ found to be associated with birthweight were related with expression of proximal genes in placenta (i.e., expression quantitative trait methylation loci, eQTMs). We tested this using a linear regression model that included each of the 15 birthweight-associated CpGs and mRNA levels of genes located $500 \mathrm{~kb}$ upstream or downstream of the CpGs. There were 272 unique transcripts within $500 \mathrm{~kb}$ from the 15 CpGs. We found 15 significant associations (FDR $<0.05$ ) between four CpGs (cg00768487, cg06155341, cg08973382, and cg24450112) and 15 unique gene transcripts (Table 2). For the majority $(12 / 15,80 \%)$ of these eQTMs, higher DNA methylation was associated with decreased gene expression. For the remaining 3 (20\%) eQTMs, higher DNA methylation was associated with increased gene expression, consistent with previous evidence that DNA methylation may not always be negatively correlated with gene expression [31]. The CpGs were located upstream relative to the promotor of the associated gene in 8/12 (67\%) of the inversely associated eQTMs but were located downstream of the promotor of the associated gene in all positively associated eQTMs. The top associations were between DNA methylation at cg00768487 (that showed increased methylation with higher birthweight in our study) and decreased expression of SH3BGRL3 and UBXN11 genes (Table 2).

\section{Correlations between expression of proximal genes and birthweight}

Next, we evaluated whether the 15 unique gene transcripts were correlated with birthweight. We found a significant inverse correlation between FOSL1 expression and birthweight ( $r=-0.25, p=0.03$ ) (Fig. 2). Notably, increased DNA methylation at cg06155341 was associated with higher birthweight (EWAS finding) and lower FOSL1 expression (eQTM finding); in parallel, lower FOSL1 expression was correlated with higher birthweight (gene expression-birthweight correlation finding) (Fig. 3). There was also a tendency for inverse correlations between $U B A$ SH3A ( $r=-0.21, p=0.07)$ and birthweight (Fig. 2).

\section{Functional annotation and regulatory enrichment}

We examined the birthweight-associated CpGs for enrichment in regulatory regions of the genome based on the ENCODE and Roadmap Projects [32]. The birthweight-associated CpGs were enriched $(p<0.05)$ in CpG island shore regions (N-Shore) $(p=0.009)$, chromatin states flanking active TSS $(p=0.009)$, and chromatin states flanking transcription at 5 ' and $3^{\prime}$ gene loci $(p=0.04)$ (Additional Table 3).

To further understand the functional relevance of the birthweight-related CpGs, we performed pathway enrichment analysis of genes annotated to the top $100 \mathrm{CpGs}$ using the ingenuity pathway analysis (IPA) tool (QIAGEN Inc., https://www.qiagenbioinformatics.com). The top enriched IPA canonical pathways included cytotoxic $\mathrm{T}$ lymphocytes, protein kinase A signaling, mTOR signaling, and virus entry via endocytic pathways. The top enriched diseases and disorders included pathways related to cancer, organismal injury and abnormalities, hematological, immunological and gastrointestinal diseases (Table 3).

We also examined the top $100 \mathrm{CpGs}$ for enrichment of overlap with tissue-specific or cell-type-specific DNase 1 hypersensitivity sites (DHSs) using experimentally derived functional element overlap analysis of regions from EWAS (eFORGE) [33]. The strongest enrichment for tissue-specific DHS was observed in placental cells $\left(p=4.34 \times 10^{-6}\right)$. Significant DHS enrichment was also found in fetal heart, fetal thymus, fetal stomach, and various cells in blood, skin and breast tissues (Additional Table 4).

\section{cis-mQTL annotation in placenta and blood}

We assessed genetic determinants of DNA methylation at the 15 birthweight-associated CpGs through a lookup of published resources of cis-methylation quantitative loci (cis-mQTLs) in placenta $[34,35]$ and in blood at 

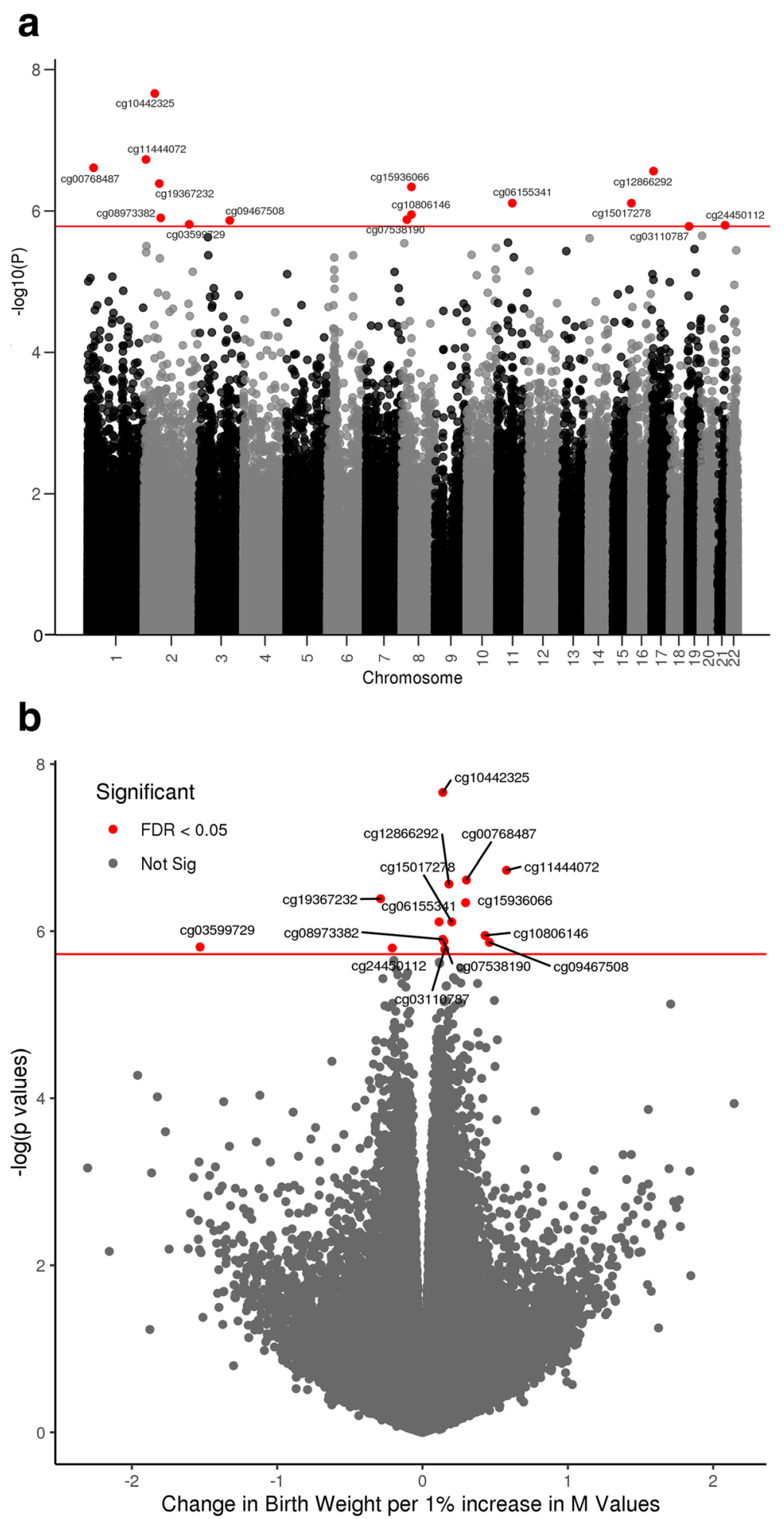

Fig. 1 Distributions of associations between CpG sites in placenta and birthweight. a Manhattan plot. b Volcano plot. Horizontal red line marks FDR 0.05; red dots denote CpGs significantly associated with birthweight 
Table 1 Placental DNA methylation CpG sites associated with birthweight

\begin{tabular}{|c|c|c|c|c|c|c|c|c|}
\hline CpG site & Chr & Position & Gene & Relation to island & Gene group & Coeff $(95 \%$ Cl) & $\boldsymbol{p}$ value & FDR $\boldsymbol{p}$ value \\
\hline $\operatorname{cg} 10442325$ & 2 & 48401950 & Intergenic & OpenSea & & $0.017(0.009,0.024)$ & $2.18 \mathrm{E}-08$ & $9.0 \mathrm{E}-03$ \\
\hline cg00768487 & 1 & 26611311 & UBXN11 & OpenSea & Body & $0.020(0.006,0.034)$ & $2.44 \mathrm{E}-07$ & $2.8 \mathrm{E}-02$ \\
\hline $\operatorname{cg} 11444072$ & 2 & 9427798 & ASAP2 & OpenSea & Body & $0.019(0.005,0.033)$ & $1.86 \mathrm{E}-07$ & $2.8 \mathrm{E}-02$ \\
\hline cg12866292 & 17 & 8079312 & TMEM107 & N_Shore & Body & $0.010(0.004,0.016)$ & $2.72 \mathrm{E}-07$ & $2.8 \mathrm{E}-02$ \\
\hline cg15936066 & 8 & 42356637 & SLC20A2 & OpenSea & $5^{\prime} U T R$ & $0.027(0.012,0.041)$ & $4.56 \mathrm{E}-07$ & $3.1 \mathrm{E}-02$ \\
\hline cg19367232 & 2 & 68478649 & PPP3R1 & N_Shore & Body & $-0.007(-0.010,-0.004)$ & $4.09 \mathrm{E}-07$ & $3.1 \mathrm{E}-02$ \\
\hline cg06155341 & 11 & 66048759 & $\mathrm{CNH} 2$ & N_Shore & Body & $0.009(0.003,0.014)$ & $7.74 \mathrm{E}-07$ & $4.0 \mathrm{E}-02$ \\
\hline cg15017278 & 16 & 127449 & $M P G$ & Island & $5^{\prime} U T R$ & $0.012(0.002,0.022)$ & $7.75 E-07$ & $4.0 \mathrm{E}-02$ \\
\hline cg03110787 & 19 & 6217641 & MLLT1 & S_Shelf & Body & $0.012(0.004,0.019)$ & $1.65 E-06$ & $4.5 \mathrm{E}-02$ \\
\hline cg03599729 & 2 & 200820225 & C2orf60 & Island & Body & $-0.003(-0.004,-0.001)$ & $1.55 \mathrm{E}-06$ & $4.5 \mathrm{E}-02$ \\
\hline cg07538190 & 8 & 22458182 & C8orf58 & S_Shore & Body & $0.011(0.003,0.019)$ & $1.33 \mathrm{E}-06$ & $4.5 \mathrm{E}-02$ \\
\hline cg08973382 & 2 & 74728623 & $\angle B X 2$ & N_Shore & Body & $0.007(0.002,0.012)$ & $1.25 \mathrm{E}-06$ & $4.5 \mathrm{E}-02$ \\
\hline cg09467508 & 3 & 137486265 & Intergenic & N_Shore & & $0.028(0.013,0.044)$ & $1.36 \mathrm{E}-06$ & $4.5 \mathrm{E}-02$ \\
\hline cg10806146 & 8 & 42356871 & SLC2OA2 & OpenSea & $5^{\prime} U T R$ & $0.041(0.020,0.062)$ & $1.13 \mathrm{E}-06$ & $4.5 \mathrm{E}-02$ \\
\hline $\operatorname{cg} 24450112$ & 21 & 44103949 & PDE9A & N_Shore & Body & $-0.026(-0.039,-0.013)$ & $1.60 E-06$ & $4.5 \mathrm{E}-02$ \\
\hline
\end{tabular}

Position: base pair position based on hg19 human reference genome

Relation to island: Shore $=0-2 \mathrm{~kb}$ from island, Shelf $=2-4 \mathrm{~kb}$ from island, $\mathrm{N}=$ upstream $\left(5^{\prime}\right)$ of $\mathrm{CpG}$ island, $\mathrm{S}=$ downstream $\left(3^{\prime}\right)$ of $\mathrm{CpG}$ island

Coeff $\%$ change in methylation beta value per $10 \mathrm{~g}$ increase in birthweight, FDR false discovery rate

serial timepoints across the life-course [36]. None of the CpGs overlap with cis-mQTLs in placenta, but cismQTLs have been found in blood for cg03110787 (MLLT1), cg12866292 (TMEM107), and cg07538190 (C8orf58) (Additional Table 5). None of the cis-mQTL single nucleotide polymorphisms (SNPs) found in blood has been reported to be associated with birthweight or adult traits in the NHGRI-EBI GWAS catalog of published GWASs [37].

We further assessed whether there are known GWAS loci for birthweight [38] in a 1-Mb window $(500 \mathrm{~kb}$ up and down stream) of each of the 15 birthweightassociated CpGs. We observed that cg11444072 (ASAP2) was located $234 \mathrm{~kb}$ and $267 \mathrm{~kb}$, respectively, from the

Table 2 Expression of genes in cis-region ( $\pm 500 \mathrm{~kb}$ ) of birthweight-associated $\mathrm{CpG}$ sites associated with DNA methylation and their correlation with birthweight

\begin{tabular}{|c|c|c|c|c|c|c|c|}
\hline \multirow[t]{2}{*}{ CpG site } & \multirow[t]{2}{*}{ Gene } & \multicolumn{4}{|c|}{$\begin{array}{l}\text { Association between gene expression and DNA } \\
\text { methylation }\end{array}$} & \multicolumn{2}{|c|}{$\begin{array}{l}\text { Correlation between gene expression and } \\
\text { birthweight }\end{array}$} \\
\hline & & Coeff & SE & $\boldsymbol{p}$ value & FDR $\boldsymbol{p}$ value & Pearson $\boldsymbol{r}$ & $\boldsymbol{p}$ value \\
\hline \multirow[t]{6}{*}{ cg00768487 (chr1) } & SH3BGRL3 & -0.00055 & 0.000108 & $2.30 E-06$ & $5.75 E-05$ & -0.145 & 0.21 \\
\hline & UBXN11 & -0.00303 & 0.000647 & $1.25 \mathrm{E}-05$ & $1.56 \mathrm{E}-04$ & -0.117 & 0.31 \\
\hline & RPS6KA1* & -0.00126 & 0.000295 & $5.53 \mathrm{E}-05$ & $4.61 \mathrm{E}-04$ & -0.127 & 0.27 \\
\hline & CD52* & -0.0015 & 0.000407 & $4.50 E-04$ & $2.81 \mathrm{E}-03$ & -0.169 & 0.14 \\
\hline & DHDDS* & -0.00112 & 0.000378 & $4.27 \mathrm{E}-03$ & $1.78 \mathrm{E}-02$ & -0.017 & 0.88 \\
\hline & ZNF683 & -0.0395 & 0.013312 & $4.06 \mathrm{E}-03$ & $1.78 \mathrm{E}-02$ & -0.056 & 0.63 \\
\hline \multirow[t]{2}{*}{ cg08973382 (chr2) } & $H K 2^{*}$ & -0.00024 & $6.43 \mathrm{E}-05$ & $2.90 E-04$ & $8.42 \mathrm{E}-03$ & -0.158 & 0.17 \\
\hline & SEMA4F* & -0.00258 & 0.000747 & $9.14 \mathrm{E}-04$ & $1.32 \mathrm{E}-02$ & -0.108 & 0.35 \\
\hline \multirow[t]{6}{*}{ cg06155341 (chr11) } & TMEM151A* & -0.05519 & 0.012548 & $3.65 \mathrm{E}-05$ & $1.61 \mathrm{E}-03$ & -0.136 & 0.24 \\
\hline & CATSPER ${ }^{*}$ & -0.00396 & 0.001153 & $9.86 \mathrm{E}-04$ & $2.17 \mathrm{E}-02$ & -0.170 & 0.14 \\
\hline & $K L C 2$ & 0.000382 & 0.000117 & $1.62 \mathrm{E}-03$ & $2.37 \mathrm{E}-02$ & 0.047 & 0.69 \\
\hline & CST6 & -0.00026 & $8.34 \mathrm{E}-05$ & $3.10 E-03$ & $3.41 \mathrm{E}-02$ & -0.064 & 0.58 \\
\hline & $R A B 1 B$ & 0.00015 & $5.14 \mathrm{E}-05$ & $4.63 E-03$ & $3.62 \mathrm{E}-02$ & 0.009 & 0.93 \\
\hline & FOSL1* & -0.00391 & 0.001349 & $4.93 \mathrm{E}-03$ & $3.62 \mathrm{E}-02$ & -0.248 & 0.03 \\
\hline cg24450112 (chr21) & UBASH3A & 0.040597 & 0.013412 & $3.41 \mathrm{E}-03$ & $4.78 \mathrm{E}-02$ & -0.209 & 0.07 \\
\hline
\end{tabular}

${ }^{*} \mathrm{CpG}$ located upstream relative to the promotor (start of gene) 

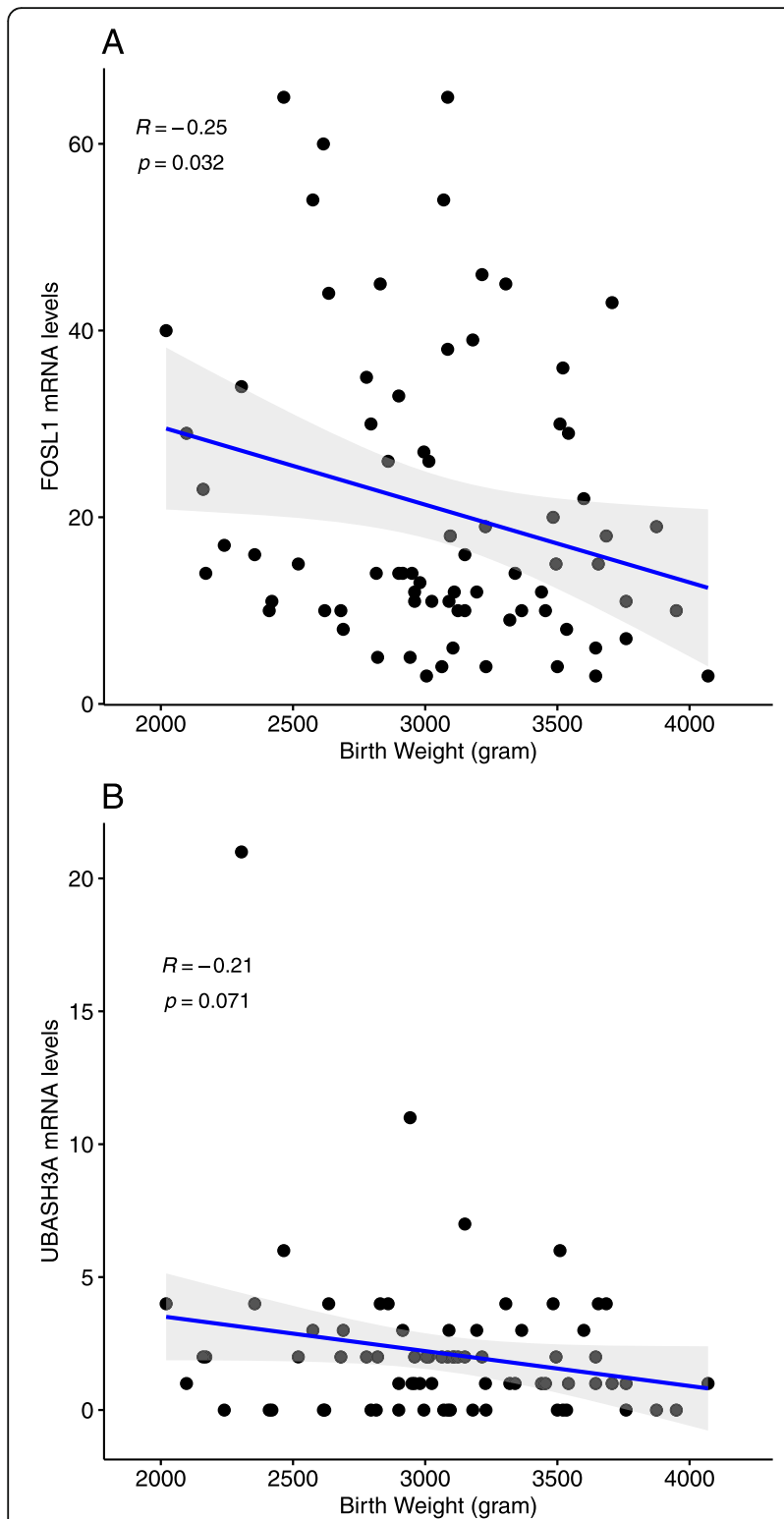

Fig. 2 Correlations between birthweight and placental expression of genes associated DNA methylation levels of birthweight-associated CpG sites. a FOSL1. b UBASH3A

birthweight-associated SNPs rs10495563 and rs11893688 (ADAM17), and cg06155341 (CNIH2) was located 454 $\mathrm{kb}$ from the birthweight-associated SNP rs7102454 (SNX32/EFEMP2). Absence of cis-acting SNPs near the majority of our CpGs shows that the associations are unlikely to be confounded by the effect of common sequence variants on birthweight.

\section{Phenotypic annotation of birthweight-associated CpGs and genes}

Using the EWAS Atlas database [39] and the NHGRI-EBI catalog of published GWASs [37], we assessed whether our birthweight-associated CpGs and annotated genes have been reported to be associated with diseases or traits. We found that cg00768487 (UBXN11) and cg03110787 (MLLT1) have been associated with papillary thyroid carcinoma [40], cg10806146 (SLC20A2) and cg15936066 (SLC20A2) with prostate cancer [41], cg15936066 (SLC20A2) with systemic lupus erythematosus [42], and cg07538190 (C8orf58) with psoriasis [43] (Fig. 4A, Additional Table 6). The CNIH2 gene is a GWAS locus for gout $[44,45]$. Out of the 15 top genes in our study, four genes (MLLT1, PDE9A, ASAP2, and SLC20A2) have been mapped to CpGs associated with birthweight in a recent cord blood EWAS meta-analysis [18]. However, the birthweight-associated CpGs annotated to the four genes in cord blood were different from the birthweightassociated placental CpGs we found. The directions of association of the cord blood CpGs were identical with the placental CpGs for MLLT1 and PDE9A but were opposite to the placental CpGs for ASAP2 and SLC2OA2.

Next, we examined whether cord blood methylation at CpGs known to be associated with birthweight [14-18] was replicated in placenta. Although no CpG was associated with birthweight at FDR $<0.05$, we observed signals of suggestive overlap (FDR $=0.055$ to 0.059 in our data) at three CpGs reported to be associated with birthweight $\left(\operatorname{cg} 01613077\right.$ in RASSF2 $\left(p=2.24 \times 10^{-6}, \mathrm{FDR}=0.055\right)$, cg24016995 in PTPRE $\left(p=3.3410^{-6}, \mathrm{FDR}=0.059\right)$, cg03047995 in FITM1 $\left(p=2.44 \times 10^{-6}\right.$, FDR $\left.\left.=0.055\right)\right)$. At cg01613077 and cg24016995, higher methylation in placenta was associated with higher birthweight in our study consistent with the published study's findings in cord blood [18]. In contrast, at cg03047995, higher methylation was associated with higher birthweight in our study but with lower birthweight in the published study in cord blood [18].

\section{Overlap with CpGs previously associated with perinatal maternal cardiometabolic traits}

Birthweight is associated with maternal perinatal cardiometabolic status [46]. Therefore, we examined our data to assess whether CpGs in offspring tissues found in previous EWAS using blood samples to be associated with maternal perinatal cardiometabolic traits (including maternal pre-pregnancy BMI $(n=1981 \mathrm{CpGs})$, hypertensive disorders of pregnancy ( $n=19 \mathrm{CpGs})$, and preeclampsia ( $n=84$ CpGs); Additional Table 7) overlap with CpGs in placenta associated with birthweight. We found $13 \mathrm{CpGs}$ for which higher DNA methylation in placenta has been related to preeclampsia in previous studies and with lower birthweight in our study (FDR <0.05). Moreover, at cg19367232 (PPP3R1), for which higher DNA methylation in neonatal cord blood has been related to maternal prepregnancy underweight in a previous study, higher DNA 


\section{Lower expression of FOSL1}

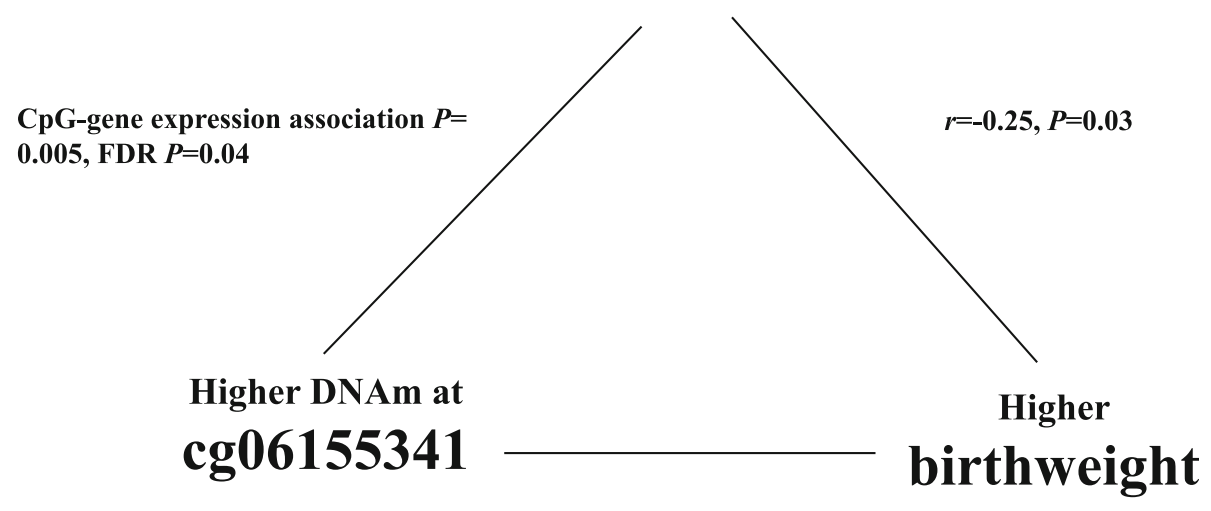

$10 \mathrm{~g}$ higher birthweight per $0.1 \%$ higher DNA methylation

CpG-birthweight $P=7.7 \times 10^{-7}$, FDR $P=0.04$

Fig. 3 Triangular relationship between DNA methylation at cg06155341, expression of FOSL1, and birthweight

methylation in placenta was associated with lower birthweight in our study (Fig. 4B, Additional Table 8).

\section{Overlap with CpGs previously associated with adult cardiometabolic traits}

Several studies have also reported that birthweight is associated with offspring risk of cardiometabolic diseases in later life [1-3]. For CpGs known to be associated with childhood/adult cardiometabolic traits in previous EWAS (including myocardial infarction ( $n=189$ CpGs), lipid traits ( $n=792 \mathrm{CpGs}$ ), blood pressure-related traits ( $n=18 \mathrm{CpGs})$, type 2 diabetes $(n=5672 \mathrm{CpGs})$, and body mass index ( $n=1079$ CpGs); Additional Table 7$)$, we examined whether DNA methylation at these CpGs in placenta was associated with birthweight. We found six CpGs for which DNA methylation in blood has been associated with adult type 2 diabetes in previous studies and DNA methylation in placenta was associated with birthweight in our study. For all the six CpGs, the methylation change related to increased risk for type 2 diabetes was associated with lower birthweight. Overlapping associations were also found for three CpGs that have been associated with lipid traits in previous studies (Fig. 4C, Additional Table 8).

\section{Discussion}

In this placental EWAS of birthweight, a developmental trait associated with morbidity in childhood and cardiometabolic and cognitive dysfunction in adults [1, 3, 4750], we identified significant differential methylation at 15 CpG sites. DNA methylation at one third of the birthweight-associated $\mathrm{CpG}$ sites was associated with expression of proximal genes in placenta. Notably, the triangular relationships observed between methylation of cg06155341, FOSL1 gene expression, and birthweight was suggestive of gene expression-mediated influence of DNA methylation on birthweight. We demonstrated that genes annotated to the top-significant CpGs were enriched in pathways including cytotoxic T-lymphocyte antigen-4 (CTLA4), protein kinase A, and mTOR signaling that play key roles in organ development, immune regulation, and cardiometabolic function in humans. Out of the 15 CpGs, methylation at five CpGs in adult blood has been associated with adult chronic diseases

Table 3 Significantly enriched pathways enriched in genes annotated to top 100 CpGs associated with birthweight

\begin{tabular}{|c|c|c|c|}
\hline Ingenuity canonical pathways & Molecules & $\boldsymbol{p}$ value & FDR $\boldsymbol{p}$ value \\
\hline Assembly of RNA polymerase I complex & POLR1E, POLR1C & $1.0 \mathrm{E}-03$ & 0.008 \\
\hline CTLA4 signaling in cytotoxic T lymphocytes & AP1G1, FGFR2, PTPN22 & $1.1 \mathrm{E}-02$ & 0.016 \\
\hline DNA methylation and transcriptional repression signaling & $\mathrm{CHD} 4, \mathrm{CHD} 3$ & $1.1 \mathrm{E}-02$ & 0.016 \\
\hline Protein kinase A signaling & FLNB, PPP3R1, PTPRE, PTPN22, ANAPC11, PDE9A & $9.0 \mathrm{E}-03$ & 0.016 \\
\hline Pyrimidine deoxyribonucleotides de novo biosynthesis I & RRM2, RRM2B & $5.0 \mathrm{E}-03$ & 0.016 \\
\hline mTOR signaling & FGFR2, PRR5L, ARHGAP8/PRR5-ARHGAP8, PRR5 & $1.5 \mathrm{E}-02$ & 0.018 \\
\hline Virus entry via endocytic pathways & FLNB, AP1G1, FGFR2 & $1.8 \mathrm{E}-02$ & 0.018 \\
\hline
\end{tabular}




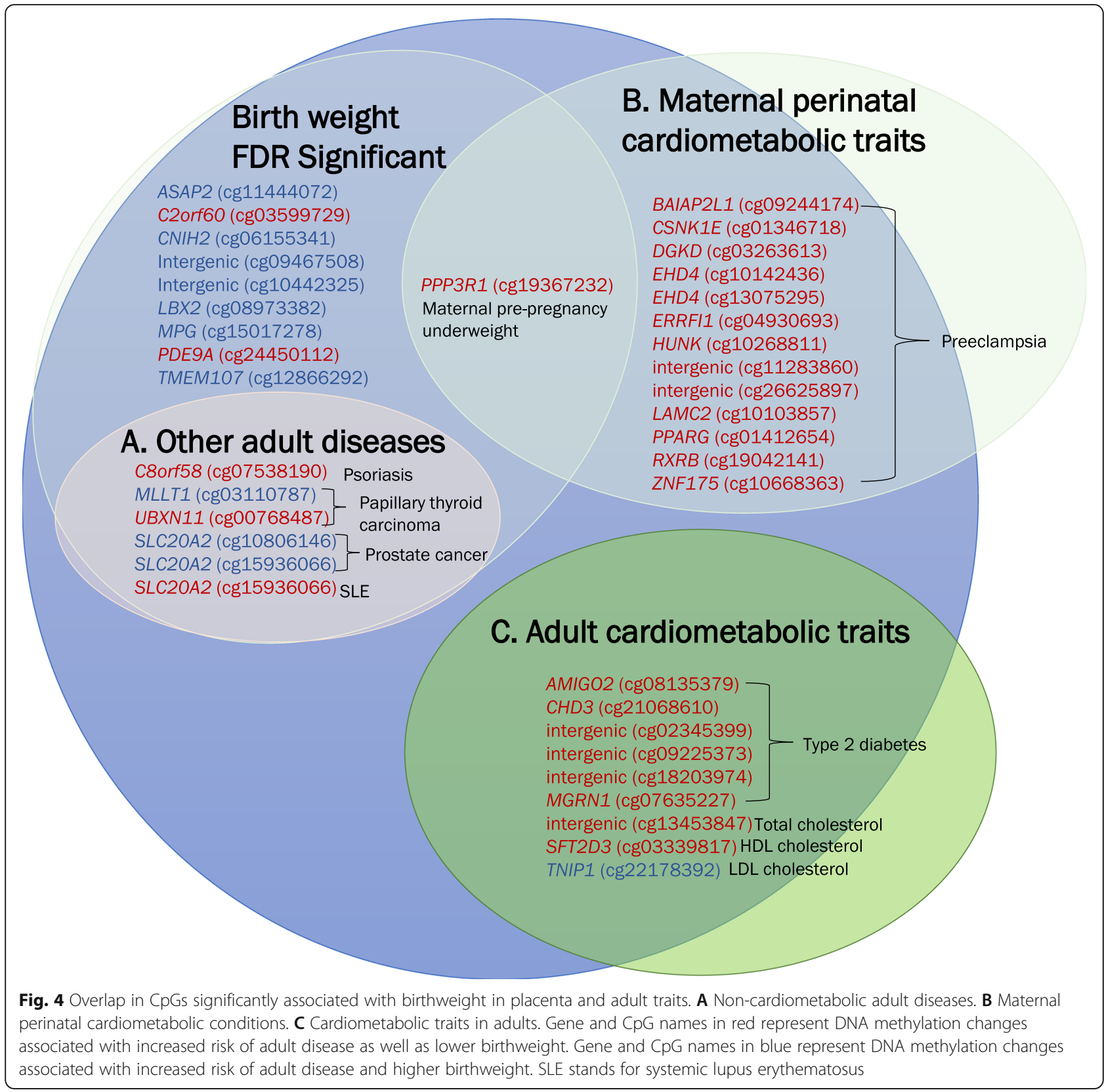

[40-43]. In addition, we observed that DNA methylation at $\mathrm{CpG}$ sites known to be associated with higher risk of maternal preeclampsia, pre-pregnancy underweight, and adult type 2 diabetes was also significantly associated with lower birthweight in our study. This is consistent with the known inverse correlations observed between these cardiometabolic conditions and birthweight. These findings suggest that placental DNA methylation at loci that play a role in birthweight regulation may be related with maternal perinatal cardiometabolic status and offspring risk of later life chronic diseases.

Previous EWASs have identified several differentially methylated CpGs in cord blood associated with birthweight [14-18]. Four genes (ASAP2, MLLT1, $P D E 9 A$, and SLC2OA2) annotating CpGs associated with birthweight in our study also annotate other CpGs reported to be associated with birthweight in a recent meta-analysis of birthweight EWASs in cord blood [18]. On the one hand, the cross-tissue portability of these genes in relation to birthweight strengthens the evidence for an important biological significance of the genes in fetal growth regulation. None of these four birthweightassociated CpGs were associated with gene expression in placenta in our study or in cord blood in the metaanalysis study [18]. Therefore, it is possible that they may have functional effects other than gene expression, 
such chromatin stability and alternative splicing which have not been investigated in our study. A recent GWAS of birthweight [38] has also identified a fetal genetic variant in ASAP2 within $250 \mathrm{~kb}$ from the CpGs associated with birthweight in our study, suggesting a potential regulatory relationship between the genetic variant and epigenetic alterations at this locus. On the other hand, the birthweight-associated CpGs annotated to the four genes differ in the two studies. Moreover, for ASAP2 and SLC2OA2, the direction of association between birthweight and DNA methylation in placenta was opposite to the direction of association previously seen in cord blood. These differences may be due to possible tissue differences in DNA methylation at CpGs associated with intrauterine influences. It may also be due to complex relationships between genetic variants and DNA methylation at different CpGs on the same gene. Future studies are needed to understand these differences and shed light on mechanisms by which CpGs on the same gene could have directionally opposite associations with birthweight in placenta and cord blood.

Genes annotating CpGs found to be associated with birthweight in our study have functions relevant for fetal growth and placental function. UBXN11 regulates cellular processes such as protein degradation. Mouse knockout of a member of the UBX family of genes resulted in early embryonic lethality suggesting that the gene is essential for fetal development [51]. An EWAS involving cardiac tissue samples has found differential methylation of a CpG in UBXN11 associated with dilated cardiomyopathy in adults [52]. TMEM107 encodes a transmembrane protein that regulates primary cilia, cell surface organelles that respond to environmental cues and play important roles in developmental processes including skeletal formation, neural crest cell formation, and differentiation [53]. SLC2OA2 encodes a protein essential for maternal to fetal phosphate transport, and deficiency of the SLC20A2 protein in mice has been associated with placental vascular defects, increased calcification and fetal growth restriction [54]. The genes for which DNA methylation at birthweight-associated CpG sites exhibited significant association with gene expression in our study are known GWAS loci for adult lipid traits (e.g., $Z D H H C 18$ ) [55], and inflammation/oxidative stress biomarker concentrations (e.g., ZNF683) [56].

FOSL1 (Fos-like antigen 1) encodes a leucin zipper protein involved in the formation of the AP-1 transcription factor complex. The FOS proteins regulate cell proliferation, differentiation and transformation [57]. FOSL1 has been implicated in bone formation [58] and is a key downstream effector of the PI3K/AKT signaling pathway that regulates placental trophoblast cell invasion [59, 60]. Trophoblast cell invasion is critical for successful placentation and remodeling of the maternal uterine vasculature and can lead to poor fetal growth and other pregnancy complications when disrupted [60]. In vitro experiment in rats has also demonstrated that FOSL1 regulates trophoblast invasion-vascular remodeling-related genes such as Sema6d [59], a member of the semaphorin family of proteins that are involved in signaling and morphogenesis. Further, we found association between DNA methylation at another birthweight-associated CpG site (cg00768487 in MLLT1) and SEMA4F gene expression, another member of the semaphorin proteins. In all, these findings suggest that the birthweight-associated DNA methylation loci identified in this study are involved in key developmental processes related to epigenetic regulation of the maternalfetal interface and fetal growth.

Interestingly, ten out of the 15 birthweight-associated CpGs found in the present study have been implicated in gestation duration at delivery by a study that identified more than 5000 CpGs associated in neonatal cord blood with gestational age [61]. Our findings are unlikely to be due to confounding by gestational age at delivery because the model was adjusted for gestational age and none of the ten CpGs were associated with gestational age in sensitivity analysis. At nine $\mathrm{CpGs}$, the direction of association of cord blood methylation with gestational age in the previous study [61] was opposite to the direction of association of placental methylation with birthweight in our study. Therefore, we speculate that the association of higher methylation at these loci with shorter duration of gestation may be related to the increased fetal size, because bigger fetal size at term gestation contributes to labor onset via enhanced mechanical uterine stretch [62] and release of fetal maturation signals [63]. Future studies are needed to understand the role of these loci in the link between fetal size and initiation of parturition.

Maternal perinatal cardiometabolic status has been associated with birthweight [46], and birthweight has been associated with offspring risk of cardiometabolic diseases in later life [1-3]. Understanding the mechanisms that underlie these links is useful to develop early interventions. We found $14 \mathrm{CpGs}$ exhibiting overlapping associations with maternal pre-pregnancy underweight and preeclampsia in previous studies and with lower birthweight in our study. It is therefore possible that DNA methylation changes at these loci may partly explain the relationships of maternal pre-pregnancy underweight and preeclampsia with lower birthweight [64]. We also found six CpGs for which DNA methylation in placenta was related to lower birthweight in the present study and with higher risk of type 2 diabetes in adult blood in previous studies, consistent with the inverse genetic correlations between birthweight and risk of type 2 diabetes [38].

This study has key strengths such as inclusion of racial/ ethnic diverse pregnant women and availability of SNP genotype data that helped adjust for genotype PCs to minimize 
bias due to population structure. The use of multiple data sources and integrated analysis of DNA methylation with transcriptomic data provided insights into potential downstream effects of the identified methylation changes. In depth in silico functional analyses facilitated functional interpretation of the findings and their relevance for adult diseases. Ours is the first study to date to examine the associations of densely profiled genome-wide DNA methylation in placenta, an important tissue in fetal growth, with birthweight.

We acknowledge that there are limitations to our study. We cannot definitively determine whether the altered DNA methylation profiles led to birthweight differences or were a response of the placenta to birthweight differences. To date, there is no reference data for cell proportion in placenta; hence, the altered DNA methylation profiles at the CpGs may be related to unmeasured heterogeneity or maturity of cells in placenta. To counter this limitation, we implemented reference-free adjustment using SVA which adjusts for technical and unmeasured confounding due cell-type proportion variation [65]. Confounding due to unknown factors associated with both placental DNA methylation and birthweight may have influence on our results. Our analysis did not detect substantially large DNA methylation changes associated with birthweight. All placental samples were obtained from deliveries at or near term (mean $\pm \mathrm{SD}$ gestational age at delivery $=39.5 \pm 1.1$ weeks); hence, to what extent the findings of this study are generalizable to earlier gestation times remains uncertain. Future studies are needed to determine the functional role of the loci discovered in the present study and larger cohorts can potentially identify additional methylation loci associated with birthweight.

\section{Conclusions}

This first placental EWAS of birthweight identified 15 DNA methylation CpGs significantly associated with birthweight, with several CpGs being associated with expression of nearby genes in placenta. Some of the birthweight-associated loci play key roles in developmental processes and have been associated with adult cardiometabolic diseases. The findings suggest that the placental genes associated with birthweight in our study may be important for understanding the molecular mechanisms linking birthweight to later life cardiometabolic diseases.

\section{Methods}

\section{Data set and study population}

The present study included 312 women who provided placenta samples at delivery as part of the Eunice Kennedy Shriver National Institute of Child Health and $\mathrm{Hu}$ man Development (NICHD) Fetal Growth StudiesSingletons. Out of the 312 women, 301 were available for analysis after quality control procedures described below. The NICHD Fetal Growth Studies-Singletons is a prospective longitudinal cohort of 2802 pregnant woman without major pre-existing medical conditions from four self-identified race/ethnic groups (i.e., nonHispanic White, non-Hispanic Black, Hispanic, and Asian or Pacific Islander) recruited from 12 clinic sites in the USA and followed through delivery $[28,66]$. Details about the study design and data collection methods have been previously reported [28, 66]. Gestational age was determined using the date of the last menstrual period and confirmed by ultrasound between 8 weeks to 13 weeks and 6 days of gestation [66]. The study was approved by institutional review boards at NICHD and each of the participating clinical sites. Written informed consent was obtained from all study participants.

\section{Birthweight measurements}

After delivery, neonates underwent standardized anthropometric measurements as previously described [67]. Birthweight was measured in grams using an infant beam-balance or digital scale.

\section{Placental sample collection and DNA methylation quantifications}

At delivery, placentas were acquired by trained research personnel. The placentas were rinsed with sterile saline and pat dried with paper towel, and nonadherent blood clots were removed. The placental membrane and umbilical cord were trimmed before biopsies were taken. Placental biopsies measuring $0.5 \mathrm{~cm} \times 0.5 \mathrm{~cm} \times 0.5 \mathrm{~cm}$ were collected directly below the fetal surface of the placenta within one hour of delivery. Samples were placed in RNALater and frozen for molecular analysis. Processing of the placental biopsies was performed at the Columbia University Irving Medical Center and details have been described previously [35]. DNA from placental biopsies was extracted and assayed using Illumina's Infinium Human Methylation450 Beadchip (Illumina Inc., San Diego, CA). Standard Illumina protocols were followed for background correction, normalization to internal control probes, and quantile normalization. Normalization was performed using the modified Beta MIxture Quantile dilation (BMIQ) method to correct the probe design bias in the Illumina Infinium Human Methylation450 Beadchip and achieve between-sample normalization $[68,69]$. The resulting intensity files were processed with Illumina's GenomeStudio, which generated average betascores (i.e., the fraction of methylated sites per sample by taking the ratio of methylated and unmethylated fluorescent signals at each queried $\mathrm{CpG}$ ) and detection $p$ values. Details of quality control filters applied on the genotype and DNA methylation data have been previously reported [29]. Beta scores with an associated detection $p$ values $\geq 0.05$ were set to missing. In 
addition, probes with mean detection $p$ value $\geq 0.05(n=$ $36)$, cross-reactive $(n=24,491)$, non-autosomal $(n=14$, 589), and CpG sites located within 20 base pairs from known single nucleotide polymorphisms (SNPs) $(n=37$, 360) were removed. After these QC procedures, 409,101 CpGs were included in the EWAS. As recommended by $\mathrm{Du}$ et al. [70], beta values for each $\mathrm{CpG}$ site (i.e., the fraction of methylated sites per sample by taking the ratio of methylated and unmethylated fluorescent signals) were logit transformed to $M$-value scale.

\section{Placental genotyping}

Placental DNA samples were genotyped using HumanOmni2.5 Beadchips (Illumina Inc., San Diego, CA), followed by initial data processing using Illumina's Genome Studio, as previously described [35]. SNPs were excluded if they had excessive missing genotype (SNPs with genotype call rate of $<95 \%$ ), deviated from HardyWeinberg equilibrium ( $p$ value $<0.0001$ ), and had low minor allele frequency $(<0.05)$. A total of 11 samples showing discrepancies between phenotypic sex and genotypic sex $(n=4)$, that were outliers from the distribution of the samples' genetic clusters based on multidimensional scaling plots $(n=6)$, and with a mismatching sample identifier $(n=1)$ were excluded.

\section{Placental RNA extraction and quantification}

RNA was extracted from 80 placentas using TRIZOL reagent (Invitrogen, MA), and sequenced using the Illumina HiSeq2000 system. The RNA sequence preprocessing procedure has been previously described [35]. Using the RNA-seq reads, the expression of the transcripts were quantified using Salmon [71]. A total of 75 samples with both methylation and RNA-seq data were included in the tests for associations between DNA methylation and gene expression, as well as covariate-adjusted associations between gene expression and birthweight.

\section{Epigenome-wide association analysis}

Epigenome-wide analyses were performed by fitting simple linear regression models on the methylation $M$ values of each $\mathrm{CpG}$ as the dependent variable and birthweight as independent variable as implemented in the R/ Bioconductor package limma, version 3.24.15. So far, there is no reference for placental cell-type composition; therefore, our model included SVA using the Combat function that has been validated to account for heterogeneity in cell-type composition [30]. Placental genomewide SNP data were used to estimate 10 genotype-based PCs representing population structure. The $\mathrm{R}$ package "prcomp" was used to calculate methylation-based PCs [72]. All analyses adjusted for gestational age at birth (continuous), neonatal sex (male, female), maternal race/ ethnicity (Hispanic, Black, White, Asian), five methylation plates representing batch of the 96-well plate on which samples were assigned, top ten genotype-based PCs based on the eigenvectors which represent most of the variance in the genotype data, top three methylation-based PCs, and 20 SVA components that represent putative cell-type composition in our samples. None of the women studied reported smoking in the 6 months prior to pregnancy. Quantile-quantile (QQ) plots of $p$ values and the corresponding genomic inflation factor $(\lambda=1.23)$ are presented in Additional Figure 1. Statistical significance was considered based on FDR of $5 \%$. The differentially methylated CpG sites were mapped to the nearby gene using R/Bioconductor package with a background reference comprising the whole set of genes present in the Illumina $450 \mathrm{k}$ platform. To simplify interpretation, we report effect estimates in the result on the original methylation values, such that effect estimates represent change in DNA methylation beta values for $1 \mathrm{~g}$ increase in birthweight.

\section{Gene expression analyses}

We performed linear regression to test the associations between DNA methylation levels ( $M$-values) of the birthweight-associated CpGs and placental gene expression of cis-genes $(500 \mathrm{~kb}$ upstream and downstream of the CpGs). The methylation-expression association analyses were done in 75 individuals that had both DNA methylation and gene expression profiles from placental samples. For the significant methylation-expression associations (FDR < 0.05), we tested whether gene expression was associated with birthweight using Pearson correlation test.

\section{Genetic correlates of DNA methylation in placenta and blood}

To examine whether genetic variants influence DNA methylation levels of the birthweight-associated CpGs, we explored the $15 \mathrm{CpGs}$ in cis-methylation quantitative locus (cis-mQTL) resources. We queried the $15 \mathrm{CpGs}$ using a list of previously published placental mQTLs $[34,35]$. For the same query in blood, we used the mQTL database (http://www.mqtldb.org/) of mQTLs at serial time points across the life-course (pregnancy, birth, childhood, adolescence, and middle age) [36]. Furthermore, we assessed whether there are genetic variants within the proximity $( \pm 500 \mathrm{~kb})$ of the birthweightassociated CpGs by exploring the relative distances between our CpGs and birthweight GWAS loci in Warrington et al. [38]. The NHGRI-EBI GWAS catalog [37] was used to assess the relevance of the identified cismQTLs in birthweight and cardiometabolic diseases.

\section{Annotation, canonical pathway, and tissue enrichment analysis}

Annotation of the nearest gene to the birthweightassociated CpGs was performed using the UCSC Genome 
Browser build hg19 (http://genome.ucsc.edu/). We performed genomic regulatory feature enrichment on the birthweight-associated CpGs using Fisher's exact test. Regulatory regions tested for enrichment included $\mathrm{CpG}$ island locations, shelves, shores, transcription factor binding sites, and regulatory features from placenta-specific 15chromatin state annotation (ChromHMM v1.9) from the ROADMAP Epigenomics Mapping Consortium [32].

Genes annotating the top $100 \mathrm{CpGs}$ associated with birthweight were included in pathway analysis using the IPA tool (QIAGEN, Redwood City, CA, USA). Gene enrichment in canonical pathways was assessed using the right-tailed Fisher's exact test. Pathways enriched at Benjamini-Hochberg corrected FDR $p<0.05$ were considered statistically significant. In addition, we explored the top 100 CpGs for enrichment of overlap with tissue-specific or cell-type-specific DNase 1 hypersensitivity sites (DHS) using eFORGE v2.0 [33]. The set of $100 \mathrm{CpGs}$ was entered as input in eFORGE and tested for enrichment for overlap with putative functional elements (DHS) compared to the consolidated ROADMAP epigenomics DHS. The enrichment analysis was performed in one thousand matched background sets, with each background set consisting 100 CpGs matched for gene and $\mathrm{CpG}$ island annotation. Enrichment above the 99.9th percentile ( $\log 10$ binomial $p \geq 3.38)$ was considered statistically significant as implemented in eFORGE.

\section{Evaluation of previously reported $\mathrm{CpG}$ sites associated with cardiometabolic traits}

We used the EWAS Atlas database [39] to assemble CpGs in offspring tissues previously reported to be associated with maternal perinatal cardiometabolic traits (pre-pregnancy BMI, hypertensive disorders of pregnancy, and preeclampsia), and CpGs in adult/child blood previously reported to be associated with adult/child cardiometabolic traits (myocardial infarction, lipid traits, blood pressurerelated traits, type 2 diabetes, and body mass index; see Additional Table 7). We queried our birthweight EWAS output to assess whether these previously reported CpGs were associated with birthweight at FDR $<0.05$.

\section{Supplementary information}

Supplementary information accompanies this paper at https://doi.org/10. 1186/s13148-020-00873-x.

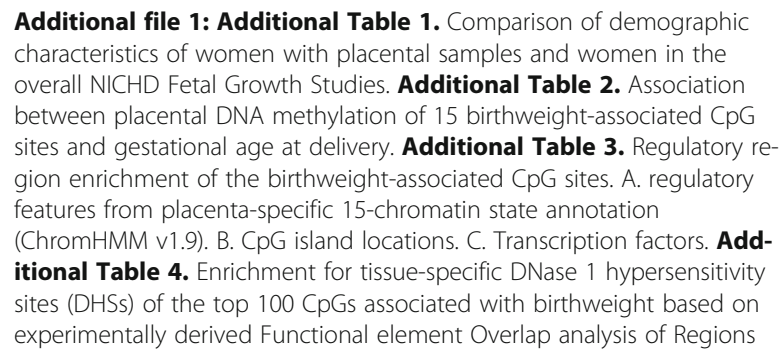

Additional file 1: Additional Table 1. Comparison of demographic characteristics of women with placental samples and women in the overall NICHD Fetal Growth Studies. Additional Table 2. Association between placental DNA methylation of 15 birthweight-associated CpG sites and gestational age at delivery. Additional Table 3. Regulatory region enrichment of the birthweight-associated $\mathrm{CpG}$ sites. A. regulatory features from placenta-specific 15-chromatin state annotation

(ChromHMM v1.9). B. CpG island locations. C. Transcription factors. Additional Table 4. Enrichment for tissue-specific DNase 1 hypersensitivity sites (DHSs) of the top 100 CpGs associated with birthweight based on experimentally derived Functional element Overlap analysis of Regions

from EWAS (eFORGE). Additional Table 5. Single nucleotide polymorphisms significantly associated with DNA methylation at three CpG sites (meQTLs) in the mQTL database (http://www.mqtldb.org/). Additional

Table 6. Previously known associations between the birthweightassociated $\mathrm{CpG}$ sites and phenotypes. Additional Table 7. Published $\mathrm{CpG}$ sites associated with maternal cardiometabolic traits and adult cardiometabolic traits. Additional Table 8. CpG sites associated with maternal cardiometabolic traits and adult cardiometabolic traits in published studies as well as with birthweight in the present study (FDR <0.05).

Additional file 2: Additional Figure 1. Quantile-quantile (QQ) plot Pvalues for associations between CpG sites in placenta and birthweight.

\section{Abbreviations}

BMI: Body mass index; CpG: Cytosine-phosphate-guanine genomic site; DHS: DNase 1 hypersensitivity site; eFORGE: Experimentally derived Functional element Overlap analysis of Regions from EWAS; eQTL: Expression quantitative trait locus; EWAS: Epigenome-wide association study; FDR: False discovery rate; GWAS: Genome-wide association study; IPA: Ingenuity pathway analysis; $\mathrm{MQTL}$ : Methylation quantitative trait locus; NHGRI: National Human Genome Research Institute; NICHD: Eunice Kennedy Shriver National Institutes of Child Health and Human Development; PC: Principal component; SNP: Single nucleotide polymorphism; SVA: Surrogate variable analysis

\section{Acknowledgements}

The authors wish to thank research teams at all participating clinical centers (which include Christina Care Health Systems; Columbia University; Fountain Valley Hospital, California; Long Beach Memorial Medical Center; New York Hospital, Queens; Northwestern University; University of Alabama at Birmingham; University of California, Irvine; Medical University of South Carolina; Saint Peters University Hospital; Tufts University; and Women and Infants Hospital of Rhode Island). The authors also acknowledge the Wadsworth Center, C-TASC, and The EMMES Corporations in providing data and imaging support. This work utilized the computational resources of the NIH HPC Biowulf cluster (http://hpc.nih.gov).

\section{Authors' contributions}

F.T.-A. conceived and designed the research idea, supervised the analysis, and wrote the manuscript. X.Z. and F.T.-A. performed statistical analyses. All authors contributed to interpretation of the results, provided critical intellectual content, and approved the final manuscript.

\section{Funding}

This research was supported by the Intramural Research Program of the Eunice Kennedy Shriver National Institute of Child Health and Human Development, National Institutes of Health, including American Recovery and Reinvestment Act funding via contract numbers HHSN275200800013C, HHSN2752008000021, HHSN27500006, HHSN275200800003IC,

HHSN275200800014C, HHSN275200800012C, HHSN275200800028C, HHSN275201000009C, and HHSN27500008. Additional support was obtained from the National Institute on Minority Health and Health Disparities and the National Institute of Diabetes and Digestive and Kidney Diseases.

\section{Availability of data and materials}

The placental DNA methylation, genotype, and gene expression data are available through dbGaP with accession number phs001717.v1.p1. The analytic codes for the current study are available upon request to the corresponding author.

Ethics approval and consent to participate

The institutional review boards at NICHD and each of the participating clinical sites approved the current study. Each woman who participated in the study provided written informed consent.

Consent for publication

Not applicable.

Competing interests

The authors declare that they have no competing interests. 


\section{Author details}

Epidemiology Branch, Division of Intramural Population Health Research, Eunice Kennedy Shriver National Institute of Child Health and Human Development, National Institutes of Health, 6710B Rockledge Dr, room 3204, Bethesda, MD 20892, USA. ²Division of Intramural Population Health Research, Eunice Kennedy Shriver National Institute of Child Health and Human Development, National Institutes of Health, Bethesda, MD, USA. ${ }^{3}$ Department of Genetics, Albert Einstein College of Medicine, Bronx, New York, USA. ${ }^{4}$ UMR 1283, Institut Pasteur de Lille, Lille, France. ${ }^{5}$ Department of Obstetrics and Gynecology, Columbia University, New York, NY, USA.

\section{Received: 5 February 2020 Accepted: 21 May 2020}

Published online: 03 June 2020

\section{References}

1. Gaskins RB, LaGasse LL, Liu J, Shankaran S, Lester BM, Bada HS, Bauer CR Das A, Higgins RD, Roberts M. Small for gestational age and higher birth weight predict childhood obesity in preterm infants. Am J Perinatol. 2010; 27:721-30.

2. Wilcox AJ, Russell IT. Birthweight and perinatal mortality: II. On weightspecific mortality. Int J Epidemiol. 1983;12:319-25.

3. Hales CN, Barker DJ, Clark PM, Cox LJ, Fall C, Osmond C, Winter PD. Fetal and infant growth and impaired glucose tolerance at age 64. BMJ. 1991;303: 1019-22.

4. Sacks DA. Determinants of fetal growth. Curr Diab Rep. 2004;4:281-7.

5. Smith ZD, Meissner A. DNA methylation: roles in mammalian development. Nat Rev Genet. 2013;14:204-20.

6. Nugent BM, Bale TL. The omniscient placenta: metabolic and epigenetic regulation of fetal programming. Front Neuroendocrinol. 2015;39:28-37.

7. Kent EM, Breathnach FM, Gillan JE, McAuliffe FM, Geary MP, Daly S, Higgins JR, Dornan J, Morrison JJ, Burke G, et al. Placental cord insertion and birthweight discordance in twin pregnancies: results of the national prospective ESPRiT Study. Am J Obstet Gynecol. 2011;205(376):e371-7.

8. Thornburg KL, O'Tierney PF, Louey S. Review: the placenta is a programming agent for cardiovascular disease. Placenta. 2010;31(Suppl): S54-9.

9. Rahnama F, Shafiei F, Gluckman PD, Mitchell MD, Lobie PE. Epigenetic regulation of human trophoblastic cell migration and invasion. Endocrinology. 2006;147:5275-83.

10. Serman L, Vlahovic M, Sijan M, Bulic-Jakus F, Serman A, Sincic N, Matijevic R, Juric-Lekic G, Katusic A. The impact of 5-azacytidine on placental weight, glycoprotein pattern and proliferating cell nuclear antigen expression in rat placenta. Placenta. 2007;28:803-11.

11. Fuke C, Shimabukuro M, Petronis A, Sugimoto J, Oda T, Miura K, Miyazaki T, Ogura C, Okazaki Y, Jinno Y. Age related changes in 5-methylcytosine content in human peripheral leukocytes and placentas: an HPLC-based study. Ann Hum Genet. 2004;68:196-204.

12. Price EM, Cotton AM, Penaherrera MS, McFadden DE, Kobor MS, Robinson W. Different measures of "genome-wide" DNA methylation exhibit unique properties in placental and somatic tissues. Epigenetics. 2012;7:652-63.

13. Novakovic B, Yuen RK, Gordon L, Penaherrera MS, Sharkey A, Moffett A, Craig JM, Robinson WP, Saffery R. Evidence for widespread changes in promoter methylation profile in human placenta in response to increasing gestational age and environmental/stochastic factors. BMC Genomics. 2011; 12:529.

14. Adkins RM, Tylavsky FA, Krushkal J. Newborn umbilical cord blood DNA methylation and gene expression levels exhibit limited association with birth weight. Chem Biodivers. 2012;9:888-99.

15. Engel SM, Joubert BR, Wu MC, Olshan AF, Haberg SE, Ueland PM, Nystad W, Nilsen RM, Vollset SE, Peddada SD, London SJ. Neonatal genome-wide methylation patterns in relation to birth weight in the Norwegian Mother and Child Cohort. Am J Epidemiol. 2014;179:834-42.

16. Simpkin AJ, Suderman M, Gaunt TR, Lyttleton O, McArdle WL, Ring SM, Tilling K, Davey Smith G, Relton CL. Longitudinal analysis of DNA methylation associated with birth weight and gestational age. Hum Mol Genet. 2015;24:3752-63.

17. Agha G, Hajj H, Rifas-Shiman SL, Just AC, Hivert MF, Burris HH, Lin X, Litonjua AA, Oken E, DeMeo DL, et al. Birth weight-for-gestational age is associated with DNA methylation at birth and in childhood. Clin Epigenetics. 2016;8:118.
18. Kupers LK, Monnereau C, Sharp GC, Yousefi P, Salas LA, Ghantous A, Page CM, Reese SE, Wilcox AJ, Czamara D, et al. Meta-analysis of epigenome-wide association studies in neonates reveals widespread differential DNA methylation associated with birthweight. Nat Commun. 2019;10:1893.

19. Michels KB, Harris HR, Barault L. Birthweight, maternal weight trajectories and global DNA methylation of LINE-1 repetitive elements. PLoS One. 2011 ; 6:e25254.

20. Bourque DK, Avila L, Penaherrera M, von Dadelszen P, Robinson WP. Decreased placental methylation at the H19/IGF2 imprinting control region is associated with normotensive intrauterine growth restriction but not preeclampsia. Placenta. 2010;31:197-202.

21. Dwi Putra SE, Reichetzeder C, Hasan AA, Slowinski T, Chu C, Kramer BK, Kleuser B, Hocher B. Being born large for gestational age is associated with increased global placental DNA methylation. Sci Rep. 2020;10:927.

22. Filiberto AC, Maccani MA, Koestler D, Wilhelm-Benartzi C, Avissar-Whiting M, Banister CE, Gagne LA, Marsit CJ. Birthweight is associated with DNA promoter methylation of the glucocorticoid receptor in human placenta. Epigenetics. 2011;6:566-72

23. Ferreira JC, Choufani S, Grafodatskaya D, Butcher DT, Zhao C, Chitayat D, Shuman C, Kingdom J, Keating S, Weksberg R. WNT2 promoter methylation in human placenta is associated with low birthweight percentile in the neonate. Epigenetics. 2011;6:440-9.

24. Leeuwerke M, Eilander MS, Pruis MG, Lendvai A, Erwich JJ, Scherjon SA, Plosch T, Eijsink JJ. DNA methylation and expression patterns of selected genes in first-trimester placental tissue from pregnancies with small-forgestational-age infants at birth. Biol Reprod. 2016;94:37.

25. Turan N, Ghalwash MF, Katari S, Coutifaris C, Obradovic Z, Sapienza C. DNA methylation differences at growth related genes correlate with birth weight: a molecular signature linked to developmental origins of adult disease? BMC Med Genet. 2012:5:10.

26. Chen PY, Chu A, Liao WW, Rubbi L, Janzen C, Hsu FM, Thamotharan S, Ganguly A, Lam L, Montoya D, et al. Prenatal growth patterns and birthweight are associated with differential DNA methylation and gene expression of cardiometabolic risk genes in human placentas: a discoverybased approach. Reprod Sci. 2018;25:523-39.

27. Banister CE, Koestler DC, Maccani MA, Padbury JF, Houseman EA, Marsit CJ. Infant growth restriction is associated with distinct patterns of DNA methylation in human placentas. Epigenetics. 2011;6:920-7.

28. Grewal J, Grantz KL, Zhang C, Sciscione A, Wing DA, Grobman WA, Newman RB, Wapner R, D'Alton ME, Skupski D, et al. Cohort profile: NICHD fetal growth studies-singletons and twins. Int J Epidemiol. 2018;47:25-25I.

29. Tekola-Ayele F, Workalemahu T, Gorfu G, Shrestha D, Tycko B, Wapner R, Zhang C, Louis GMB. Sex differences in the associations of placental epigenetic aging with fetal growth. Aging (Albany NY). 2019;11:5412-32.

30. Leek JT, Johnson WE, Parker HS, Jaffe AE, Storey JD. The sva package for removing batch effects and other unwanted variation in high-throughput experiments. Bioinformatics. 2012;28:882-3.

31. Hu S, Wan J, Su Y, Song Q, Zeng Y, Nguyen HN, Shin J, Cox E, Rho HS, Woodard C, et al. DNA methylation presents distinct binding sites for human transcription factors. Elife. 2013;2:e00726.

32. Roadmap Epigenomics C, Kundaje A, Meuleman W, Ernst J, Bilenky M, Yen A, Heravi-Moussavi A, Kheradpour P, Zhang Z, Wang J, et al. Integrative analysis of 111 reference human epigenomes. Nature. 2015:518:317-30.

33. Breeze CE, Reynolds AP, van Dongen J, Dunham I, Lazar J, Neph S, Vierstra J, Bourque G, Teschendorff AE, Stamatoyannopoulos JA, Beck S. eFORGE v2.0: updated analysis of cell type-specific signal in epigenomic data. Bioinformatics. 2019:35:4767-9.

34. Peng S, Deyssenroth MA, Di Narzo AF, Lambertini L, Marsit CJ, Chen J, Hao K. Expression quantitative trait loci (eQTLs) in human placentas suggest developmental origins of complex diseases. Hum Mol Genet. 2017;26:3432-41.

35. Delahaye F, Do C, Kong Y, Ashkar R, Salas M, Tycko B, Wapner R, Hughes F. Genetic variants influence on the placenta regulatory landscape. PLoS Genet. 2018;14:e1007785

36. Gaunt TR, Shihab HA, Hemani G, Min JL, Woodward G, Lyttleton O, Zheng J, Duggirala A, McArdle WL, Ho K, et al. Systematic identification of genetic influences on methylation across the human life course. Genome Biol. 2016; $17: 61$

37. Welter D, MacArthur J, Morales J, Burdett T, Hall $\mathrm{P}$, Junkins $H$, Klemm A, Flicek P, Manolio T, Hindorff L, Parkinson H. The NHGRI GWAS catalog, a curated resource of SNP-trait associations. Nucleic Acids Res. 2014:42: D1001-6. 
38. Warrington NM, Beaumont RN, Horikoshi M, Day FR, Helgeland O, Laurin C, Bacelis J, Peng S, Hao K, Feenstra B, et al. Maternal and fetal genetic effects on birth weight and their relevance to cardio-metabolic risk factors. Nat Genet. 2019;51:804-14.

39. Li M, Zou D, Li Z, Gao R, Sang J, Zhang Y, Li R, Xia L, Zhang T, Niu G, et al. EWAS Atlas: a curated knowledgebase of epigenome-wide association studies. Nucleic Acids Res. 2019;47:D983-8.

40. Bisarro Dos Reis M, Barros-Filho MC, Marchi FA, Beltrami CM, Kuasne H, Pinto CAL, Ambatipudi S, Herceg Z, Kowalski LP, Rogatto SR. Prognostic classifier based on genome-wide DNA methylation profiling in welldifferentiated thyroid tumors. J Clin Endocrinol Metab. 2017;102:4089-99.

41. Aref-Eshghi E, Schenkel LC, Ainsworth P, Lin H, Rodenhiser DI, Cutz JC, Sadikovic B. Genomic DNA methylation-derived algorithm enables accurate detection of malignant prostate tissues. Front Oncol. 2018:8:100.

42. Imgenberg-Kreuz J, Carlsson Almlof J, Leonard D, Alexsson A, Nordmark G, Eloranta ML, Rantapaa-Dahlqvist S, Bengtsson AA, Jonsen A, Padyukov L, et al. DNA methylation mapping identifies gene regulatory effects in patients with systemic lupus erythematosus. Ann Rheum Dis. 2018;77:73643.

43. Chandra A, Senapati S, Roy S, Chatterjee G, Chatterjee R. Epigenome-wide DNA methylation regulates cardinal pathological features of psoriasis. Clin Epigenetics. 2018;10:108.

44. Matsuo H, Yamamoto K, Nakaoka H, Nakayama A, Sakiyama M, Chiba T, Takahashi A, Nakamura T, Nakashima H, Takada Y, et al. Genome-wide association study of clinically defined gout identifies multiple risk loci and its association with clinical subtypes. Ann Rheum Dis. 2016;75:652-9.

45. Nakayama A, Nakaoka H, Yamamoto K, Sakiyama M, Shaukat A, Toyoda Y, Okada Y, Kamatani Y, Nakamura T, Takada T, et al. GWAS of clinically defined gout and subtypes identifies multiple susceptibility loci that include urate transporter genes. Ann Rheum Dis. 2017;76:869-77.

46. Palinski W. Effect of maternal cardiovascular conditions and risk factors on offspring cardiovascular disease. Circulation. 2014;129:2066-77.

47. Rossen LM, Schoendorf KC. Trends in racial and ethnic disparities in infant mortality rates in the United States, 1989-2006. Am J Public Health. 2014; 104:1549-56.

48. Mikkola K, Ritari N, Tommiska V, Salokorpi T, Lehtonen L, Tammela O, Paakkonen L, Olsen P, Korkman M, Fellman V. Neurodevelopmental outcome at 5 years of age of a national cohort of extremely low birth weight infants who were born in 1996-1997. Pediatrics. 2005;116:1391-400.

49. Barker DJ, Godfrey KM, Osmond C, Bull A. The relation of fetal length, ponderal index and head circumference to blood pressure and the risk of hypertension in adult life. Paediatr Perinat Epidemiol. 1992;6:35-44.

50. Godfrey KM, Barker DJ. Fetal nutrition and adult disease. Am J Clin Nutr. 2000;71:1344S-52S.

51. Hu Y, O'Boyle K, Auer J, Raju S, You F, Wang P, Fikrig E, Sutton RE. Multiple UBXN family members inhibit retrovirus and lentivirus production and canonical NFkappaBeta signaling by stabilizing IkappaBalpha. PLoS Pathog 2017;13:e1006187.

52. Meder B, Haas J, Sedaghat-Hamedani F, Kayvanpour E, Frese K, Lai A, Nietsch R, Scheiner C, Mester S, Bordalo DM, et al. Epigenome-wide association study identifies cardiac gene patterning and a novel class of biomarkers for heart failure. Circulation. 2017;136:1528-44.

53. Cela P, Hampl M, Shylo NA, Christopher KJ, Kavkova M, Landova M, Zikmund T, Weatherbee SD, Kaiser J, Buchtova M. Ciliopathy protein Tmem107 plays multiple roles in craniofacial development. J Dent Res 2018;97:108-17

54. Norris AA, Lewis AJ, Zeitlin IJ. Changes in colonic tissue levels of inflammatory mediators in a guinea-pig model of immune colitis. Agents Actions. 1982:12:243-6.

55. Willer CJ, Schmidt EM, Sengupta S, Peloso GM, Gustafsson S, Kanoni S, Ganna A, Chen J, Buchkovich ML, Mora S, et al. Discovery and refinement of loci associated with lipid levels. Nat Genet. 2013:45:1274-83.

56. Benjamin EJ, Dupuis J, Larson MG, Lunetta KL, Booth SL, Govindaraju DR, Kathiresan S, Keaney JF Jr, Keyes MJ, Lin JP, et al. Genome-wide association with select biomarker traits in the Framingham Heart Study. BMC Med Genet. 2007;8(Suppl 1):S11.

57. Eferl R, Wagner EF. AP-1: a double-edged sword in tumorigenesis. Nat Rev Cancer. 2003:3:859-68.

58. Fleischmann A, Hafezi F, Elliott C, Reme CE, Ruther U, Wagner EF. Fra-1 replaces C-Fos-dependent functions in mice. Genes Dev. 2000:14:2695-700.
59. Kent LN, Rumi MA, Kubota K, Lee DS, Soares MJ. FOSL1 is integral to establishing the maternal-fetal interface. Mol Cell Biol. 2011:31:4801-13.

60. Renaud SJ, Kubota K, Rumi MA, Soares MJ. The FOS transcription factor family differentially controls trophoblast migration and invasion. J Biol Chem. 2014;289:5025-39

61. Bohlin J, Haberg SE, Magnus P, Reese SE, Gjessing HK, Magnus MC, Parr CL, Page CM, London SJ, Nystad W. Prediction of gestational age based on genome-wide differentially methylated regions. Genome Biol. 2016;17:207.

62. Shynlova O, Tsui P, Dorogin A, Lye SJ. Monocyte chemoattractant protein-1 (CCL-2) integrates mechanical and endocrine signals that mediate term and preterm labor. J Immunol. 2008;181:1470-9.

63. Condon JC, Jeyasuria P, Faust JM, Mendelson CR. Surfactant protein secreted by the maturing mouse fetal lung acts as a hormone that signals the initiation of parturition. Proc Natl Acad Sci U S A. 2004;101:4978-83.

64. Han Z, Mulla S, Beyene J, Liao G, McDonald SD, Knowledge Synthesis G. Maternal underweight and the risk of preterm birth and low birth weight: a systematic review and meta-analyses. Int J Epidemiol. 2011;40:65-101.

65. Dhana K, Braun KVE, Nano J, Voortman T, Demerath EW, Guan W, Fornage $M$, van Meurs JBJ, Uitterlinden AG, Hofman A, et al. An epigenome-wide association study of obesity-related traits. Am J Epidemiol. 2018;187:1662-9.

66. Buck Louis GM, Grewal J, Albert PS, Sciscione A, Wing DA, Grobman WA, Newman RB, Wapner R, D'Alton ME, Skupski D, et al. Racial/ethnic standards for fetal growth: the NICHD Fetal Growth Studies. Am J Obstet Gynecol. 2015;213:449 e441.

67. Buck Louis GM, Zhai S, Smarr MM, Grewal J, Zhang C, Grantz KL, Hinkle SN, Sundaram R, Lee $S$, Honda M, et al. Endocrine disruptors and neonatal anthropometry, NICHD Fetal Growth Studies - Singletons. Environ Int. 2018; 119:515-26.

68. Horvath S. DNA methylation age of human tissues and cell types. Genome Biol. 2013;14:3156.

69. Teschendorff AE, Marabita F, Lechner M, Bartlett T, Tegner J, Gomez-Cabrero D, Beck S. A beta-mixture quantile normalization method for correcting probe design bias in Illumina Infinium 450 k DNA methylation data. Bioinformatics. 2012;29:189-96

70. Du P, Zhang X, Huang CC, Jafari N, Kibbe WA, Hou L, Lin SM. Comparison of beta-value and M-value methods for quantifying methylation levels by microarray analysis. BMC Bioinformatics. 2010;11:587.

71. Patro R, Duggal G, Love MI, Irizarry RA, Kingsford C. Salmon provides fast and bias-aware quantification of transcript expression. Nat Methods. 2017; 14:417.

72. Akalin A, Kormaksson M, Li S, Garrett-Bakelman FE, Figueroa ME, Melnick A, Mason CE. methylKit: a comprehensive R package for the analysis of genome-wide DNA methylation profiles. Genome Biol. 2012;13:R87.

\section{Publisher's Note}

Springer Nature remains neutral with regard to jurisdictional claims in published maps and institutional affiliations.

Ready to submit your research? Choose BMC and benefit from:

- fast, convenient online submission

- thorough peer review by experienced researchers in your field

- rapid publication on acceptance

- support for research data, including large and complex data types

- gold Open Access which fosters wider collaboration and increased citations

- maximum visibility for your research: over $100 \mathrm{M}$ website views per year

At BMC, research is always in progress.

Learn more biomedcentral.com/submission 